\title{
Role of glucose metabolism related gene GLUT1 in the occurrence and prognosis of colorectal cancer
}

\author{
Wenming Feng ${ }^{1}$, Ge Cui ${ }^{2}$, Cheng-Wu Tang ${ }^{1}$, Xiao-Lan Zhang ${ }^{2}$, Chuang Dai ${ }^{3}$, Yong- \\ Qiang $\mathrm{Xu}^{3}$, Hui Gong ${ }^{4}$, Tao Xue ${ }^{4}$, Hui-Hui Guo ${ }^{4}$ and Ying $\mathrm{Bao}^{3}$ \\ ${ }^{1}$ Department of Hepatobiliary Pancreatic Surgery, The First Affiliated Hospital of Huzhou University, Huzhou, Zhejiang \\ Province, P.R. China \\ ${ }^{2}$ Department of Pathology, The First Affiliated Hospital of Huzhou University, Huzhou, Zhejiang Province, P.R. China \\ ${ }^{3}$ Department of Surgery, The First Affiliated Hospital of Huzhou University, Huzhou, Zhejiang Province, P.R. China \\ ${ }^{4}$ Central Laboratory, The First Affiliated Hospital of Huzhou University, Huzhou, Zhejiang Province, P.R. China \\ Correspondence to: Ying Bao, email: baoyingzj@21cn.com
}

Keywords: colorectal cancer, GLUT1, polymorphism, prognosis

Received: March 24, $2017 \quad$ Accepted: April 21, $2017 \quad$ Published: May 23, 2017

Copyright: Feng et al. This is an open-access article distributed under the terms of the Creative Commons Attribution License 3.0 (CC BY 3.0), which permits unrestricted use, distribution, and reproduction in any medium, provided the original author and source are credited.

\section{ABSTRACT}

Colorectal cancer (CRC) ranks the third most commonly diagnosed cancer in males and the second in females worldwide. However, the functional and causal SNPs for CRC remain to be mined. Glucose transporter 1 (GLUT1), a pivotal ratelimiting element in the transport of glucose in malignancy cells, has been identified to be associated with many cancers. Here, we aim to explore the role of GLUT1 in the occurrence and prognosis of colorectal cancer in a Chinese population. We found that GLUT1 expression levels in CRC tumor tissues were significantly higher than those in the corresponding adjacent normal tissues, and Cox multivariate analysis demonstrated that the GLUT1 expression was an independent prognostic factor for CRC (HR $=2.11,95 \% C I=1.33-3.34, P=0.001)$. For a functional polymorphism of GLUT1 (rs710218), we found that individuals with TT genotype (OR $=1.68,95 \%$ CI $=1.02-2.75, P=0.041)$ or $A T$ genotype $(O R=1.47,95 \% C I=1.09-1.99, P=0.012)$ of rs710218 had a significantly increased risk of CRC compared to those with AA homozygote. These findings strongly suggest that glucose metabolism related gene GLUT1, and its functional SNP, rs710218 might contribute to CRC susceptibility and prognosis, and the exact biological mechanism awaits further research.

\section{INTRODUCTION}

Colorectal cancer (CRC) ranks the third most commonly diagnosed cancer in males and the second in females worldwide [1]. According to newly published "Cancer Statistics, 2017" of United States, the estimated new CRC cases were 135,430 , and the new deaths were 50,260 in 2017 [2]. In china, the annual CRC cases were 376.3 thousands, while the deaths were 191.0 thousands [3]. CRC has become a major public health problem. It is well established that CRC is a complex trait caused by genetic and environmental factors and their interactions
[4-6]. Genome-wide association studies (GWASs) have identified numerous susceptibility loci for CRC, however, most risk variants are located in non-coding regions without clear biological mechanisms [7-13]. Thus, the functional and causal SNPs for CRC remain to be mined.

Glucose transporter 1 (GLUT1), also named facilitates glucose transporter member 1 (SLC2A1), has been demonstrated to be a pivotal rate-limiting element in the transport of glucose in malignancy cells and overexpressed in different types of human cancers [1419]. Oh et al. [20] also found that glut1 could promote cell proliferation, migration and invasion by regulating 
epidermal growth factor receptor and integrin signaling in triple-negative breast cancer cells. It was also a prognostic molecular biomarkers for patients with colorectal cancer liver metastasis [21]. Recently, a meta-analysis also revealed that the expression status of GLUT1 was a vital prognostic indicator and promising therapeutic target in solid tumors [22]. A functional polymorphism (GLUT1 rs710218), which is localized in the promoter region and 2841 bp upstream of the start of exon 1 of GLUT1, consists of an A to T substitution and is closely positioned to a number of putative binding sites for transcription factors, including HIF-1alpha [23]. Previous studies have been conducted to evaluated associations between SNP rs710218 and susceptibility of hepatocellular carcinoma, diabetic nephropathy, breast cancer, in-stent restenosis, and clear-cell renal carcinoma [23-27]. Here, we aim to explore the role of glucose metabolism related gene GLUT1 in the occurrence and prognosis of colorectal cancer in a Chinese population.

\section{RESULTS}

\section{Characteristics of study populations}

The characteristics of the study participants were summarized in Table 1 . Totally 368 CRC cases and 500 healthy controls were included in this study. No significant differences were found between cases and controls for age, gender, smoking status, and drinking status. However, CRC cases have higher Body mass index and Waist-hipratio than healthy controls $(\mathrm{P}<0.001)$. More tumors were located at Colon, while TNM stage II and III account for $76.4 \%$ of all CRC cases.

\section{GLUT1 expression and CRC susceptibility}

Firstly, we examined GLUT1 level in CRC tumor tissues. The expression of GLUT1 in tumor tissues relative to adjacent normal tissues is shown in Figure 1. Among all the 368 pairs of CRC patients, GLUT1 expression levels in CRC tumor tissues were significantly higher than those in the corresponding adjacent normal tissues $(\mathrm{P}<0.001)$, which indicates that GLUT1 contributes to the susceptibility of CRC.

\section{GLUT1 predicts poor prognosis in CRC patients}

In order to further evaluate the value of GLUT1 in prognosis of patients with CRC, we used Kaplan-Meier survival analysis and log-rank test. These 368 CRC patients were classified into relatively high or low GLUT1 expression group using the median level of GLUT1 in CRC tissues as a cut-off value. As shown in Figure 2, the increased expression of GLUT1 was significantly associated with poor survival of CRC $(\mathrm{P}=0.001)$. After adjusting for age, gender, smoking status, drinking status, body mass index, and waist-hip-ratio, Cox multivariate analysis demonstrated that the GLUT1 expression was an independent prognostic factor for CRC $(\mathrm{HR}=2.11,95 \%$ $\mathrm{CI}=1.33-3.34, \mathrm{P}=0.001)$.

\section{Association analysis between individual SNP and CRC risk}

As shown in Table 2, GLUT1 rs710218 was evidently associated with increased CRC risk. Under multivariable logistic regression model adjusted for age, gender, smoking status, drinking status, body mass index, and waist-hip-ratio, individuals with TT genotype (OR = $1.68,95 \% \mathrm{CI}=1.02-2.75, \mathrm{P}=0.041)$ or AT genotype $(\mathrm{OR}$ $=1.47,95 \% \mathrm{CI}=1.09-1.99, \mathrm{P}=0.012)$ of $\mathrm{rs} 710218 \mathrm{had}$ a significantly increased risk of CRC compared to those with AA homozygote. In dominant model, TT genotype was significant associated with increased $\mathrm{CRC}$ risk $(\mathrm{OR}=$ $1.51,95 \% \mathrm{CI}=1.13-2.00, \mathrm{P}=0.005)$. Likewise, positive outcome was found in the additive models, with per-Tallele OR of $1.37(95 \% \mathrm{CI}=1.09-1.71, \mathrm{P}=0.006)$. Results of Figure 3, which presents comparison between rs710218 and GLUT1 expression, also indicated that T allele was significantly associated with higher GLUT1 expression $(\mathrm{P}<0.001)$ and then contributed to $\mathrm{CRC}$ risk.

\section{DISCUSSION}

The current study explored association between glucose metabolism related gene GLUT1 and the occurrence and prognosis of colorectal cancer in a Chinese population; and it also evaluated a functional SNP of GLUT1, rs710218 might contribute to CRC susceptibility. To be best of our knowledge, this should be the first study aiming to evaluate association of the expression of GLUT1 and CRC in Chinese population, and also should be the first genetic association study about polymorphism of GLUT1 and CRC risk.

Glucose metabolism was closely related with carcinogenesis of CRC [28-31]. Early in 1981, Ingram et al. [32] has reported that glucose could increase experimentally induced colorectal cancer. Since, many experimental and epidemiological studies have concluded their relationship [31, 33-38]. In 1999, In the Cardiovascular Health Study cohort of 5849 participants, Schoen et al. [35] found that Individuals in the highest quartile of fasting glucose had a nearly twofold increased risk of CRC, and the linear trend RR for fasting glucose level was statistically significant. That should be the first direct evidence of an association between elevated visceral adipose tissue level, its associated metabolic effects, and colorectal cancer [35]. GLUT1, a uniporter protein encoded by the SLC2A1 gene in humans, is in charge of facilitating the transport of glucose across 
Table 1: The characteristics of the study population

\begin{tabular}{|c|c|c|c|}
\hline Variables & Cases $(n=368)$ & Controls $(n=500)$ & P value \\
\hline \multicolumn{4}{|l|}{ Age } \\
\hline & $52.8 \pm 5.5$ & $52.9 \pm 5.6$ & 0.791 \\
\hline \multicolumn{4}{|l|}{ Gender } \\
\hline Male & 213 & 285 & 0.795 \\
\hline Female & 155 & 215 & \\
\hline \multicolumn{4}{|l|}{ Smoking status } \\
\hline Smokers & 125 & 141 & 0.068 \\
\hline Non-smokers & 243 & 359 & \\
\hline \multicolumn{4}{|l|}{ Alcohol status } \\
\hline Drinkers & 139 & 179 & 0.551 \\
\hline Non-drinkers & 229 & 321 & \\
\hline \multicolumn{4}{|l|}{ Body mass index } \\
\hline & $24.2 \pm 2.5$ & $23.1 \pm 2.4$ & $\mathbf{P}<0.001$ \\
\hline \multicolumn{4}{|l|}{ Waist-hip-ratio } \\
\hline & $0.82 \pm 0.004$ & $0.81 \pm 0.005$ & $\mathrm{P}<0.001$ \\
\hline \multicolumn{4}{|l|}{ Tumor site } \\
\hline Colon & 207 & & \\
\hline Rectum & 161 & & \\
\hline \multicolumn{4}{|l|}{ TNM stage } \\
\hline I & 60 & & \\
\hline II & 114 & & \\
\hline III & 167 & & \\
\hline IV & 27 & & \\
\hline
\end{tabular}

the plasma membranes of mammalian cells [39]. The expression levels of GLUT1 in cell membranes could be increased by reduced glucose levels and decreased by increased glucose levels [40]. Recent study showed that elevated expression of TrpC5 and GLUT1 is associated with chemo-resistance in CRC patients [41]. In current study, we found that GLUT1 expression levels in CRC tumor tissues were significantly higher than those in the corresponding adjacent normal tissues, and Cox multivariate analysis demonstrated that the GLUT1 expression was an independent prognostic factor for CRC. These results were consistent with the finding the metaanalysis by Wang et al. [22], although no studies have evaluated the association between GLUT1 expression and $\mathrm{CRC}$ prognosis in Chinese population.
SNP rs 710218 was located in the promoter region of the GLUT1 gene (-2841) closely positioned to a hypoxic response element (HRE) as putative HIF-1alpha binding site [24]. Page et al. [27] found that there was a highly significant decrease in the A-2841 genotype $(\mathrm{P}=0.0004)$ in the promoter region of those patients with CCRCC compared to the control population, while Thomas et al. [26] identified that rs710218 is not associated with a higher risk for HCC but rather for HCC progression. In current study, our findings, that rs 710218 was significantly associated with increased risk of CRC, were consistent with conclusion of Page et al. [27]. Further replication in different population and ethnics are warranted.

In conclusion, our results indicate that the expression status of GLUT1 in CRC tumor tissues were significantly 
A

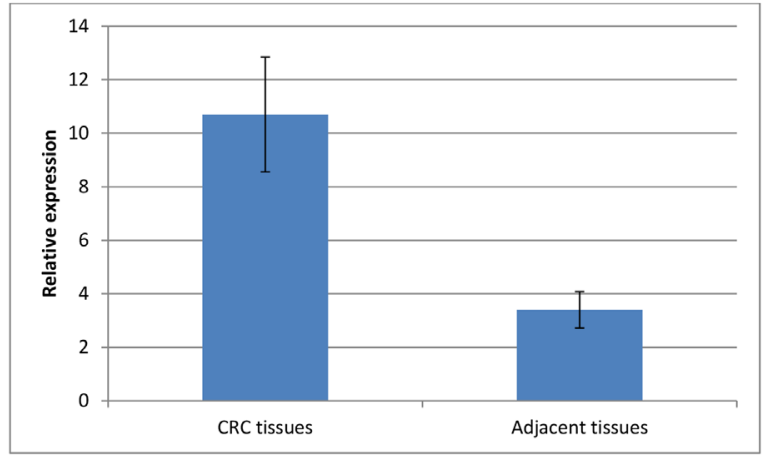

B
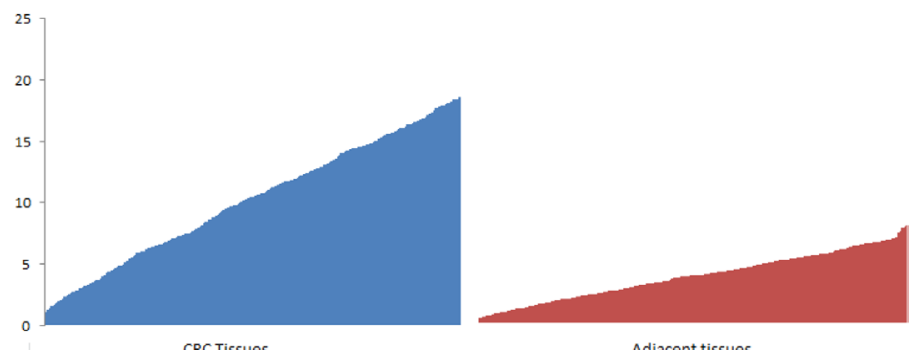

Adjacent tissues

Figure 1: GLUT1 expression is up-regulated in CRC tissues. (A) Mean value \pm SD and (B) inter-individual variability in gene expression levels.

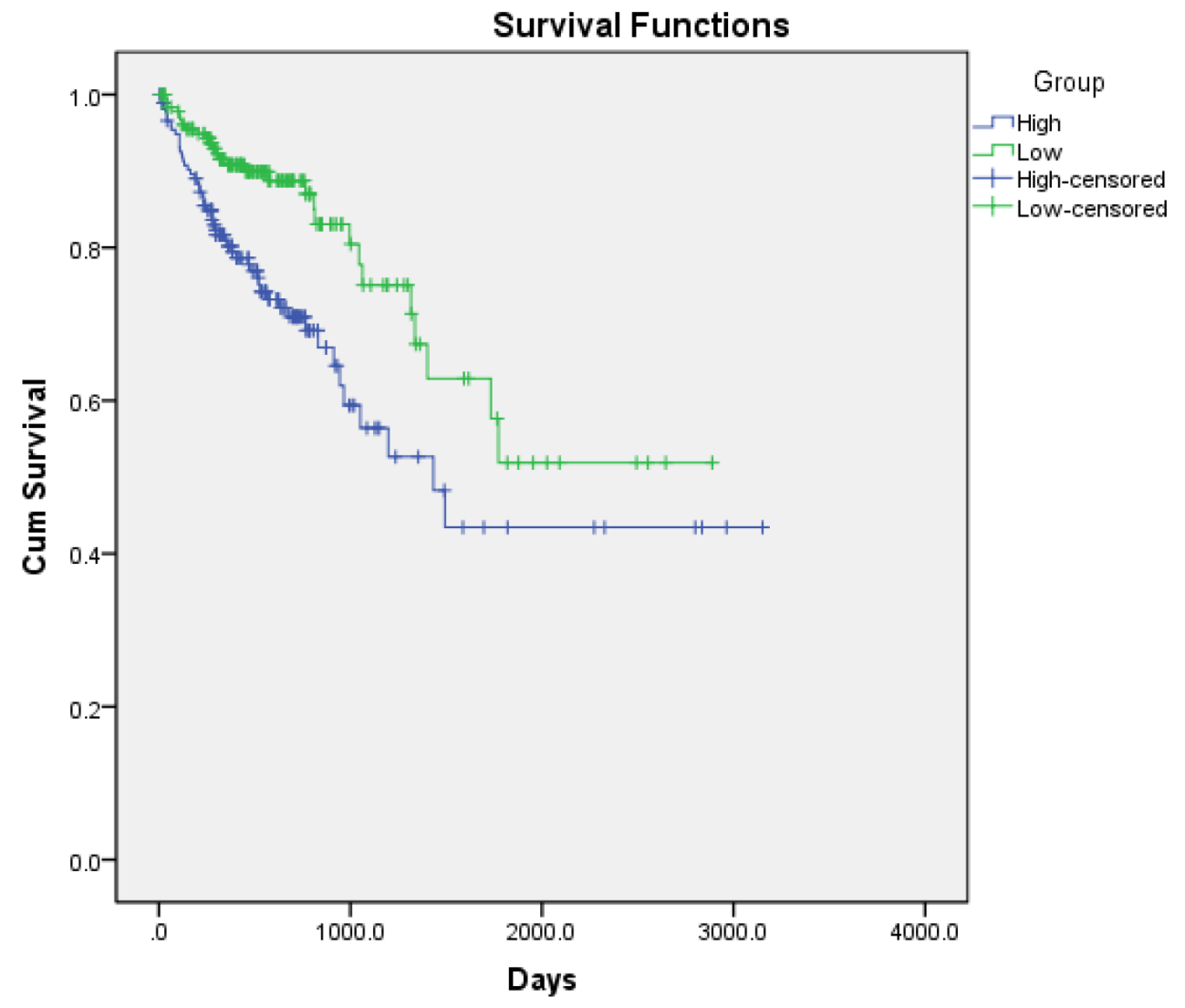

Figure 2: Kaplan-Meier overall survival curves for 368 CRC patients classified according to relative GLUT1 expression levels in CRC tissues. 
Table 2: Associations of GLUT1 rs710218 with CRC risk

\begin{tabular}{lcccc}
\hline & CRC cases & Controls & OR (95\% CIs) * & P value \\
\hline AA & 156 & 258 & 1.00 (Reference) & \\
AT & 173 & 202 & $1.47(1.09-1.99)$ & $\mathbf{0 . 0 1 2}$ \\
TT & 39 & 40 & $1.68(1.02-2.75)$ & $\mathbf{0 . 0 4 1}$ \\
T vs A & & & $1.37(1.09-1.71)$ & $\mathbf{0 . 0 0 6}$ \\
TT+AT vs AA & $212 / 156$ & $242 / 258$ & $1.51(1.13-2.00)$ & $\mathbf{0 . 0 0 5}$ \\
TT vs AT+AA & $39 / 329$ & $40 / 460$ & $1.42(.086-2.33)$ & 0.168 \\
\hline
\end{tabular}

* Adjusted for age, gender, smoking status, drinking status, body mass index, and waist-hip-ratio.

higher than those in the corresponding adjacent normal tissues, and increased expression of GLUT1 was significantly associated with poor survival of CR. These results made it could be used as a promising biomarker of occurrence and unfavorable prognosis for CRC. We also found SNP rs710218, a functional variant in the promoter region of the GLUT1 gene, was significantly associated with increased risk of CRC. Further exploration on its function is needed to clarify the biological mechanism behind.

\section{PATIENTS AND METHODS}

\section{Study subjects}

A total of 868 participants were enrolled in the present study. The case group consisted of 368 clinically and pathologically confirmed CRC patients, and 500 healthy checkup individuals were selected as the controls, which were matched by age, and gender. Demographic data, such as individual's age, gender, smoking, drinking, anthropometric measures, and pathological features, were collected by a face to face interview. Meanwhile, $5 \mathrm{~mL}$ peripheral blood from each individual was collected for genomic DNA extraction, and tissues were immediately snap-frozen in liquid nitrogen and stored at $-80{ }^{\circ} \mathrm{C}$ until total RNA was extracted for gene expression assay. The study was approved by Research Ethics Committee of the hospital, and written informed consent was obtained from all patients.

\section{Tissue RNA extraction and quantitative RT-PCR analysis}

Total RNA from frozen tissues were isolated with TRIzol reagent (Invitrogen, Carlsbad, CA, USA) according to the manufacturer's protocol. The quality

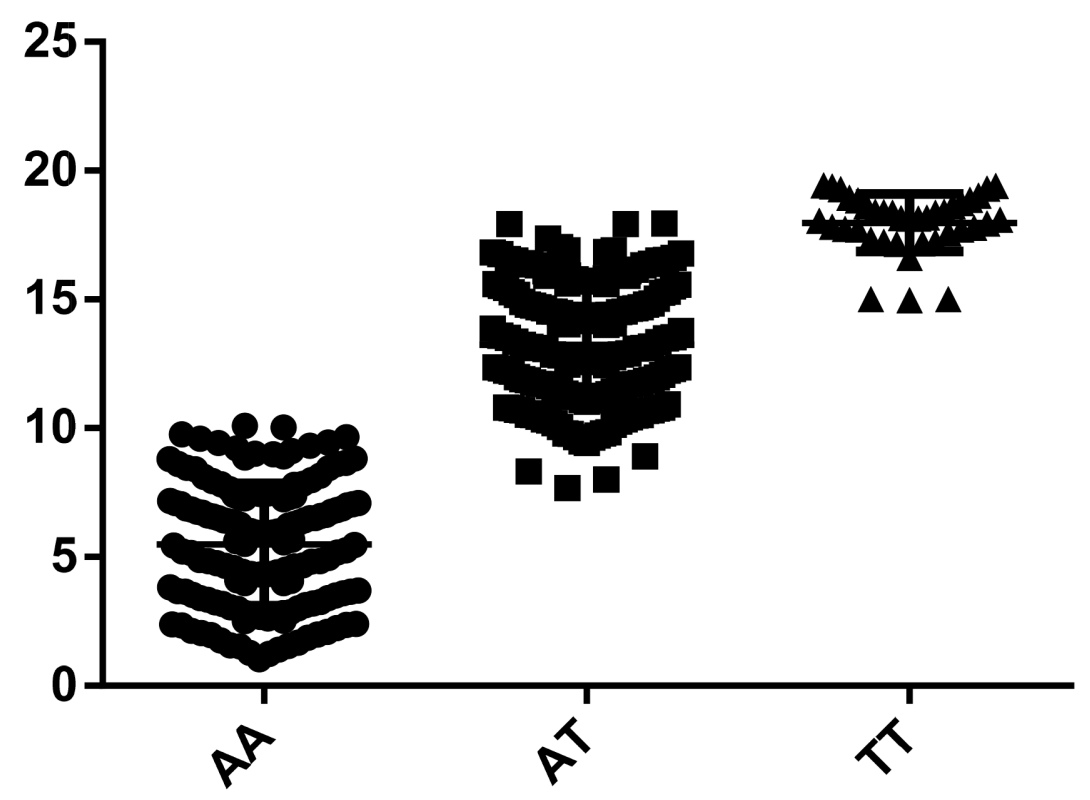

Figure 3: Comparison between rs710218 and GLUT1 expression. 
of the RNA samples were measured using Agilent 2100 bioanalyzer. Only samples that have an Integrity Number value above 6.0 that indicate acceptable RNA integrity for RT-PCR assays can be included in the study. Or the RNA would be extracted again. Then, RNA was reverse transcribed to cDNA by using a PrimeScript RT reagent Kit (Takara, Dalian, China). The SYBR Premix Ex Taq (Takara, Dalian, China) was used to detect GLUT1 expression according to the manufacturer's instructions. Real-time PCR and data collection were performed on ABI 7500. We have searched for a most suitable reference gene using NormFinder, which indicated GAPDH was suitable. Then the relative gene expression levels of GLUT1 were normalized to the expression of GAPDH, and calculated utilizing the $2^{-\Delta \mathrm{Ct}}$ method.

\section{DNA extraction and genotyping}

Genomic DNA specimens were prepared from $200 \mu \mathrm{L}$ blood using the QIAamp blood kit following the manufacturer's instructions (Qiagen, Hilden, Germany). The genotype analysis was performed using SEQUENOM's MassARRAY iPLEX assay according to the instructions of the manufacturer. For quality control, To validate the genotyping method, we also analyzed 5\% randomly selected DNA samples by direct sequencing; the results for these 2 methods were $100 \%$ concordant. Also, approximately $5 \%$ of the total DNA samples were randomly selected for genotyping in duplicate by two independent technicians to confirm a $100 \%$ consistency.

\section{Statistical analysis}

Demographic difference for the patients and controls were compared using Student's t-test and the chi-square test for the continuous variables and categorical variables, respectively. The Hardy-Weinberg equilibrium (HWE) for each candidate variant was assessed by a goodness-of-fit $\chi 2$ test in the control group. The associations of genetic factors and CRC risks were estimated by logistic regression model with adjustment for age, gender, smoking status, drinking status, body mass index, and waist-hip-ratio. The survival curves were estimated using the Kaplan-Meier method. The log-rank test was used to estimate the significance of the differences between the survival curves. A Cox proportional hazards analysis was performed to calculate the hazard ratio (HR) and the $95 \%$ confidence interval (CI) to evaluate the association between GLUT1 expression and overall survival time (OS). All statistical analyses were performed with SPSS 13.0 (IBM Corporation, Armonk, NY) and all P values were two sided with $\mathrm{P}<0.05$ considered significant.

\section{ACKNOWLEDGMENTS}

This study was supported by: 1. Medical Scientific Research Project of Zhejiang Province (Province-Ministry Co-Trained) (No: 2015PYA011); 2. Public Welfare Technical Applied Research Project of Zhejiang Province (No.2014C33135); 3. Natural Science Foundation of Zhejiang Province (No. LQ16C080001); 4. Medical Scientific Research Project of Zhejiang Province, China (No: 2015KYB372); 5. Public Welfare Technical Applied Research Project of Huzhou City (Key Program) (No. 2015GZ14); 6. Public Welfare Technical Applied Research Project of Zhejiang Province, China (Laboratory Animal Research) (No: 2017C).

\section{CONFLICTS OF INTEREST}

The authors declare that they have no conflicts of interest.

\section{REFERENCES}

1. Torre LA, Bray F, Siegel RL, Ferlay J, Lortet-Tieulent J, Jemal A. Global cancer statistics, 2012. CA Cancer J Clin. 2015; 65:87-108.

2. Siegel RL, Miller KD, Jemal A. Cancer statistics, 2017. CA Cancer J Clin. 2017; 67:7-30.

3. Chen W, Zheng R, Baade PD, Zhang S, Zeng H, Bray F, Jemal A, Yu XQ, He J. Cancer statistics in China, 2015. CA Cancer J Clin. 2016; 66:115-132.

4. Tomlinson IP, Webb E, Carvajal-Carmona L, Broderick P, Howarth K, Pittman AM, Spain S, Lubbe S, Walther A, Sullivan K, Jaeger E, Fielding S, Rowan A, et al. A genome-wide association study identifies colorectal cancer susceptibility loci on chromosomes 10p14 and 8q23.3. Nat Genet. 2008; 40:623-630.

5. Houlston RS, Webb E, Broderick P, Pittman AM, Di Bernardo MC, Lubbe S, Chandler I, Vijayakrishnan J, Sullivan K, Penegar S, Carvajal-Carmona L, Howarth K, Jaeger E, et al. Meta-analysis of genome-wide association data identifies four new susceptibility loci for colorectal cancer. Nat Genet. 2008; 40:1426-1435.

6. Zanke BW, Greenwood CM, Rangrej J, Kustra R, Tenesa A, Farrington SM, Prendergast J, Olschwang S, Chiang T, Crowdy E, Ferretti V, Laflamme P, Sundararajan S, et al. Genome-wide association scan identifies a colorectal cancer susceptibility locus on chromosome 8q24. Nat Genet. 2007; 39:989-994.

7. Ke J, Lou J, Chen X, Li J, Liu C, Gong Y, Yang Y, Zhu Y, Zhang Y, Tian J, Chang J, Zhong R, Gong J, et al. Identification of a functional variant for colorectal cancer risk mapping to chromosome 5q31.1. Oncotarget. 2016; 7:35199-35207. doi: 10.18632/oncotarget.9298. 
8. Tan C, Hu W, Huang Y, Zhou J, Zheng S. Risk of eighteen genome-wide association study-identified genetic variants for colorectal cancer and colorectal adenoma in Han Chinese. Oncotarget. 2016; 7:77651-77663. doi: 10.18632/ oncotarget. 12750.

9. Schmit SL, Schumacher FR, Edlund CK, Conti DV, Ihenacho U, Wan P, Van Den Berg D, Casey G, Fortini BK, Lenz HJ, Tusie-Luna T, Aguilar-Salinas CA, Moreno-Macias $\mathrm{H}$, et al. Genome-wide association study of colorectal cancer in Hispanics. Carcinogenesis. 2016; 37:547-556.

10. Carvajal Carmona LG, Tomlinson I. The hunting of the snark: whither genome-wide association studies for colorectal cancer? Gastroenterology. 2016; 150:1528-1530.

11. Jiang K, Sun Y, Wang C, Ji J, Li Y, Ye Y, Lv L, Guo Y, Guo S, Li H, Zhang L, Zhou Y, Jiang B, et al. Genomewide association study identifies two new susceptibility loci for colorectal cancer at 5q23.3 and $17 \mathrm{q} 12$ in Han Chinese. Oncotarget. 2015; 6:40327-40336. doi: 10.18632/ oncotarget.5530.

12. Li Z, Yu D, Gan M, Shan Q, Yin X, Tang S, Zhang S, Shi Y, Zhu Y, Lai M, Zhang D. A genome-wide assessment of rare copy number variants in colorectal cancer. Oncotarget. 2015; 6:26411-26423. doi: 10.18632/oncotarget.4621.

13. Schumacher FR, Schmit SL, Jiao S, Edlund CK, Wang H, Zhang B, Hsu L, Huang SC, Fischer CP, Harju JF, Idos GE, Lejbkowicz F, Manion FJ, et al. Genome-wide association study of colorectal cancer identifies six new susceptibility loci. Nat Commun. 2015; 6:7138.

14. Wang Y, Yun Y, Wu B, Wen L, Wen M, Yang H, Zhao L, Liu W, Huang S, Wen N, Li Y. FOXM1 promotes reprogramming of glucose metabolism in epithelial ovarian cancer cells via activation of GLUT1 and HK2 transcription. Oncotarget. 2016; 7:47985-47997. doi: 10.18632/oncotarget.10103.

15. Phadngam S, Castiglioni A, Ferraresi A, Morani F, Follo C, Isidoro C. PTEN dephosphorylates AKT to prevent the expression of GLUT1 on plasmamembrane and to limit glucose consumption in cancer cells. Oncotarget. 2016; 7:84999-85020. doi: 10.18632/oncotarget.13113.

16. Jiang J, Geng G, Yu X, Liu H, Gao J, An H, Cai C, Li N, Shen D, Wu X, Zheng L, Mi Y, Yang S. Repurposing the anti-malarial drug dihydroartemisinin suppresses metastasis of non-small-cell lung cancer via inhibiting NF-kappaB/ GLUT1 axis. Oncotarget. 2016; 7:87271-87283. doi: 10.18632/oncotarget.13536.

17. Shibuya K, Okada M, Suzuki S, Seino M, Seino S, Takeda H, Kitanaka C. Targeting the facilitative glucose transporter GLUT1 inhibits the self-renewal and tumorinitiating capacity of cancer stem cells. Oncotarget. 2015; 6:651-661. doi: 10.18632/oncotarget.2892.

18. Li QQ, Sun YP, Ruan CP, Xu XY, Ge JH, He J, Xu ZD, Wang Q, Gao WC. Cellular prion protein promotes glucose uptake through the Fyn-HIF-2alpha-Glut1 pathway to support colorectal cancer cell survival. Cancer Sci. 2011; 102:400-406.
19. Khandani AH, Whitney KD, Keller SM, Isasi CR, Donald Blaufox M. Sensitivity of FDG PET, GLUT1 expression and proliferative index in bronchioloalveolar lung cancer. Nucl Med Commun. 2007; 28:173-177.

20. Oh S, Kim H, Nam K, Shin I. Glutl promotes cell proliferation, migration and invasion by regulating epidermal growth factor receptor and integrin signaling in triple-negative breast cancer cells. BMB Rep. 2016.

21. Goos JA, de Cuba EM, Coupe VM, Diosdado B, Delis-Van Diemen PM, Karga C, Belien JA, Menke-Van der Houven van Oordt CW, Geldof AA, Meijer GA, Hoekstra OS, Fijneman RJ. Glucose transporter 1 (SLC2A1) and vascular endothelial growth factor A (VEGFA) predict survival after resection of colorectal cancer liver metastasis. Ann Surg. 2016; 263:138-145.

22. Wang J, Ye C, Chen C, Xiong H, Xie B, Zhou J, Chen Y, Zheng S, Wang L. Glucose transporter GLUT1 expression and clinical outcome in solid tumors: a systematic review and meta-analysis. Oncotarget. 2017; 8:16875-16886. doi: 10.18632/oncotarget.15171.

23. Osadnik T, Strzelczyk J, Bujak K, Regula R, Wasilewski J, Fronczek M, Kurek A, Gawlita M, Gonera M, Gierlotka M, Lekston A, Hawranek M, Myrda K, et al. Functional polymorphism rs710218 in the gene coding GLUT1 protein is associated with in-stent restenosis. Biomark Med. 2015; 9:743-750.

24. Amann T, Kirovski G, Bosserhoff AK, Hellerbrand C. Analysis of a promoter polymorphism of the GLUT1 gene in patients with hepatocellular carcinoma. Mol Membr Biol. $2011 ; 28: 182-186$.

25. Cui W, Du B, Zhou W, Jia Y, Sun G, Sun J, Zhang D, Yuan $\mathrm{H}, \mathrm{Xu} F$, Lu X, Luo P, Miao L. Relationship between five GLUT1 gene single nucleotide polymorphisms and diabetic nephropathy: a systematic review and meta-analysis. Mol Biol Rep. 2012; 39:8551-8558.

26. Bravata V, Stefano A, Cammarata FP, Minafra L, Russo G, Nicolosi S, Pulizzi S, Gelfi C, Gilardi MC, Messa C. Genotyping analysis and (1)(8)FDG uptake in breast cancer patients: a preliminary research. J Exp Clin Cancer Res. 2013; 32:23.

27. Page $\mathrm{T}$, Hodgkinson $\mathrm{AD}$, Ollerenshaw $\mathrm{M}$, Hammonds JC, Demaine AG. Glucose transporter polymorphisms are associated with clear-cell renal carcinoma. Cancer Genet Cytogenet. 2005; 163:151-155.

28. Fang S, Fang X. Advances in glucose metabolism research in colorectal cancer. Biomed Rep. 2016; 5:289-295.

29. Xu J, Ye Y, Wu H, Duerksen-Hughes P, Zhang H, Li P, Huang J, Yang J, Wu Y, Xia D. Association between markers of glucose metabolism and risk of colorectal cancer. BMJ Open. 2016; 6:e011430.

30. Chen GQ, Tang CF, Shi XK, Lin CY, Fatima S, Pan XH, Yang DJ, Zhang G, Lu AP, Lin SH, Bian ZX. Halofuginone inhibits colorectal cancer growth through suppression of Akt/ mTORC1 signaling and glucose metabolism. Oncotarget. 2015; 6:24148-24162. doi: 10.18632/oncotarget.4376. 
31. Flamen P, Stroobants S, Van Cutsem E, Dupont P, Bormans G, De Vadder N, Penninckx F, Van Hoe L, Mortelmans L. Additional value of whole-body positron emission tomography with fluorine-18-2-fluoro-2-deoxy-Dglucose in recurrent colorectal cancer. J Clin Oncol. 1999; 17:894-901.

32. Ingram DM, Castleden WM. Glucose increases experimentally induced colorectal cancer: a preliminary report. Nutr Cancer. 1981; 2:150-152.

33. Visvikis D, Francis DL, Costa DC, Mulligan R, Townsend C, Arulampalam TH, Islam MS, Taylor I, Ell PJ. Glucose utilisation and cell proliferation in colorectal cancer. Eur J Nucl Med Mol Imaging. 2002; 29:280.

34. Nilsen TI, Vatten LJ. Prospective study of colorectal cancer risk and physical activity, diabetes, blood glucose and BMI: exploring the hyperinsulinaemia hypothesis. Br J Cancer. 2001; 84:417-422.

35. Schoen RE, Tangen CM, Kuller LH, Burke GL, Cushman M, Tracy RP, Dobs A, Savage PJ. Increased blood glucose and insulin, body size, and incident colorectal cancer. J Natl Cancer Inst. 1999; 91:1147-1154.

36. Crippa F, Gavazzi C, Bozzetti F, Chiesa C, Pascali C, Bogni A, De Sanctis V, Decise D, Schiavini M, Cucchetti
G, Bombardieri E. The influence of blood glucose levels on $[18 \mathrm{~F}]$ fluorodeoxyglucose (FDG) uptake in cancer: a PET study in liver metastases from colorectal carcinomas. Tumori. 1997; 83:748-752.

37. McKeown-Eyssen G. Epidemiology of colorectal cancer revisited: are serum triglycerides and/or plasma glucose associated with risk? Cancer Epidemiol Biomarkers Prev. 1994; 3:687-695.

38. Holroyde CP, Skutches CL, Boden G, Reichard GA. Glucose metabolism in cachectic patients with colorectal cancer. Cancer Res. 1984; 44:5910-5913.

39. Olson AL, Pessin JE. Structure, function, and regulation of the mammalian facilitative glucose transporter gene family. Annu Rev Nutr. 1996; 16:235-256.

40. Seidner G, Alvarez MG, Yeh JI, O'Driscoll KR, Klepper J, Stump TS, Wang D, Spinner NB, Birnbaum MJ, De Vivo DC. GLUT-1 deficiency syndrome caused by haploinsufficiency of the blood-brain barrier hexose carrier. Nat Genet. 1998; 18:188-191.

41. Wang T, Ning K, Lu TX, Hua D. Elevated expression of TrpC5 and GLUT1 is associated with chemoresistance in colorectal cancer. Oncol Rep. 2017; 37:1059-1065. 